\title{
The Wismut Remediation Project
}

\author{
M. Lersow Wismut GmbH, Germany \\ P. Schmidt Wismut GmbH, Germany
}

\section{BACKGROUND}

In 1947, the Soviet occupation forces in Germany established the state-run stockholding company (SAG) Wismut. Run by the Soviet military, the company's sole aim was the exploitation of the East German uranium deposits for the Soviet nuclear programme. During the early "wild" years, uranium mining in Saxony and Thuringia was characterized by poor working conditions, complete disregard for the environmental concerns of the densely populated areas, and a destructive exploitation of natural and human resources. Founded in 1954, the new bi-national Soviet-German company (SDAG) Wismut continued uranium mining with a workforce of up to 120000 employees. However, in the wake of the German reunification in 1990, more than 40 years of intensive uranium mining and milling came to an end. During that period, the Wismut company had produced a total of 231000 tonnes of uranium. In global terms, this ranks WISMUT in post-war uranium production as number three, after the United States and Canada as first and second, respectively.

In 1991, the Soviet Union relinquished its shares under the terms of a state treaty. The Federal Republic of Germany took over the stock shares to $100 \%$ and also assumed the responsibility for the remediation of the devastated area. Under provision of the Wismut Act, the former SDAG Wismut was legally transferred into a company under German corporate law (Wismut $\mathrm{GmbH}$ ). The sole shareholder became the Federal Republic of Germany, represented by the Federal Ministry of Economics and Technology. Subsequently, the Ministry took measures to restructure the company and to establish a company charged with the decommissioning of mining and milling installations and with remediation of the sites. Various affiliated mine support companies, e.g. mechanical engineering, structural steelwork, consulting, civil engineering, and logistics, were split from WISMUT and successfully privatised.

In 1991, the Wismut Remediation Project was launched. The sheer size of the Project is illustrated by the legacies left by the intensive uranium production (see Table 1). It is worth stating that the remediation is similarly time- and work-consuming as the former uranium production itself.

Table $1 \quad$ Uranium production legacies at WISMUT sites

\begin{tabular}{|c|c|c|c|c|c|}
\hline \multicolumn{2}{|l|}{ Site } & $\begin{array}{l}\text { Aue, } \\
\text { Pöhla }\end{array}$ & Königstein & Ronneburg & $\begin{array}{c}\text { Seelingstädt, } \\
\text { Crossen }\end{array}$ \\
\hline \multicolumn{2}{|l|}{ Plant area } & 570 ha & 140 ha & 1670 ha & $1310 \mathrm{ha}$ \\
\hline \multirow[t]{3}{*}{ Mine dumps } & number & 20 & 3 & 16 & 9 \\
\hline & area & 370 ha & 40 ha & 600 ha & 530 ha \\
\hline & volume & 47 million $\mathrm{m}^{3}$ & 4.5 million $\mathrm{m}^{3}$ & 188 million $\mathrm{m}^{3}$ & 72 million $\mathrm{m}^{3}$ \\
\hline \multirow[t]{3}{*}{ Tailings ponds } & number & 1 & 3 & 3 & 7 \\
\hline & area & $3.5 \mathrm{ha}$ & $4.6 \mathrm{ha}$ & 9 ha & 710 ha \\
\hline & volume & 0.3 million $\mathrm{m}^{3}$ & 0.2 million $\mathrm{m}^{3}$ & 0.25 million $\mathrm{m}^{3}$ & 160 million $\mathrm{m}^{3}$ \\
\hline \multirow[t]{2}{*}{ Open pit mine } & area & & & 160 ha & \\
\hline & volume & & & 84 million $\mathrm{m}^{3}$ & \\
\hline
\end{tabular}

\section{THE REHABILITATION TASK}

Rehabilitating large-sized radioactively contaminated sites formerly operated by WISMUT in Saxony and Thuringia is one of the largest ecological and economic challenges facing the united Germany up to this 
time. The Project involves remediation at different sites located in distances from the WISMUT headquarters in Chemnitz from $40 \mathrm{~km}$ (Aue site) to $100 \mathrm{~km}$ (Königstein mine) as illustrated in Figure 1.

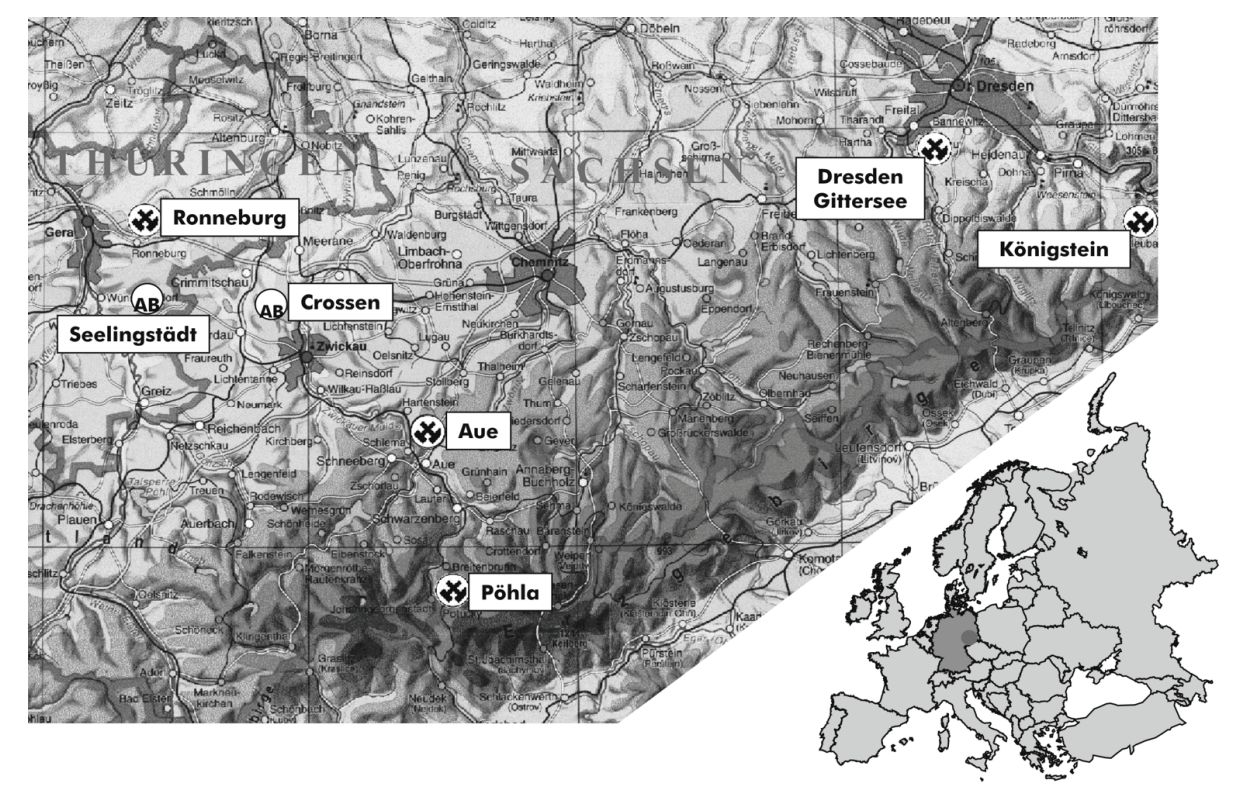

Figure 1 The WISMUT mining and milling sites

In terms of complexity and size, the WISMUT project is unique even by international standards. Although activities within this complex environmental remediation tasks are related to single objects, each site has a unique set of clean-up problems that represent a total of more than a thousand challenging individual projects.

The risks to be minimized or even removed within the Project are:

- Radiological risks and risks posed by chemo-toxic substances via the air and water pathways.

- Geo-technical risks.

- Risks due to releases of contaminants into groundwater aquifers and surface waters.

The principal ways to remove risks or to minimize them are:

- Removal of the sources of hazardous substances (e.g. by excavation and relocation to a safe site).

- Minimization of the release rates and mitigation of the dispersion of hazardous substances (e.g. by cover construction, by encapsulation).

- Immobilisation of contaminants (e.g. by water treatment).

WISMUT started the Remediation Project in the early 1990s by conduct of the following measures:

- Implementation of emergency actions to eliminate immediate harmful effects (1990 - 1992).

- Investigation of the inventory of contamination (large-scale investigations, establishment of the socalled WISMUT Environmental Register, 1990 - 1993).

- Development of site-specific conceptions for the remediation (1991 - 1995), first assessments of the overall costs (1991).

- Decision on the principle ways to rehabilitate large objects or classes of objects (1991 - 1997).

- Preparation and implementation of the first remedial measures (since 1991).

- Establishment of a monitoring system, documentation of measures, development of methods to prove the remediation success. 
The large-scale operation is funded by the federal government, which earmarked a total of $€ 6.2$ billion to conduct an environmentally and economically sound rehabilitation. The total budget is allocated by the Federal Ministry of Economics and Technology in the form of annual funds. On the basis of these funds, WISMUT establishes each year a financial plan which includes in detail the funds to be spent for remediation of individual objects. The budget for 2006 amounts to $€ 198$ million.

The overall project includes abandonment and flooding of underground mines, relocation and covering of waste rock piles, dewatering and geo-chemical stabilisation of structures and buildings, site clearance and rehabilitation. In the following selected examples the complexity of the remediation at WISMUT sites will be presented in more detail (Lersow, 2006).

\section{WASTE ROCK PILE REMEDIATION AND REFILLING OF AN OPEN PIT AT THE RONNEBURG SITE}

In the remediation of waste rock piles, in general two different approaches are possible. Technically most challenging is the option of excavating and relocation of the entire waste rock material to a mined-out open pit or to engineered sites. In cases where relocation is not feasible on technical or financial reasons, the insitu remediation by re-shaping (stabilization of slopes), covering and establishing of plants is the option to be applied (Hagen et al., 2005).

Waste rock pile remediation at the Ronneburg site takes advantage of the fact that the Lichtenberg open pit requires backfilling. From Figure 2 it becomes discernible that backfilling is already in an advanced stage. This figure shows the sequence of waste rock pile relocation into the Lichtenberg open pit carried out from 1993 up to the present and the works still to be done until end of 2007. For the relocation WISMUT operated (and is still continuing to operate) a sizeable and powerful fleet of earth-moving equipment to load, haul and place waste rock material into the Lichtenberg open pit. The fleet of 22 dump trucks - some carrying up to 136 tonnes - is on the job hauling more than 40000 cubic metres of waste rock daily. After termination of the relocation in 2007, all waste rock material will be relocated and the pit will be completely filled. The body of relocated material will be built with a cap $60 \mathrm{~m}$ above the initial open pit edge level. Finally, a cover of inert material $(0.5 \mathrm{~m}$ thick) will be placed on the waste rock material body.

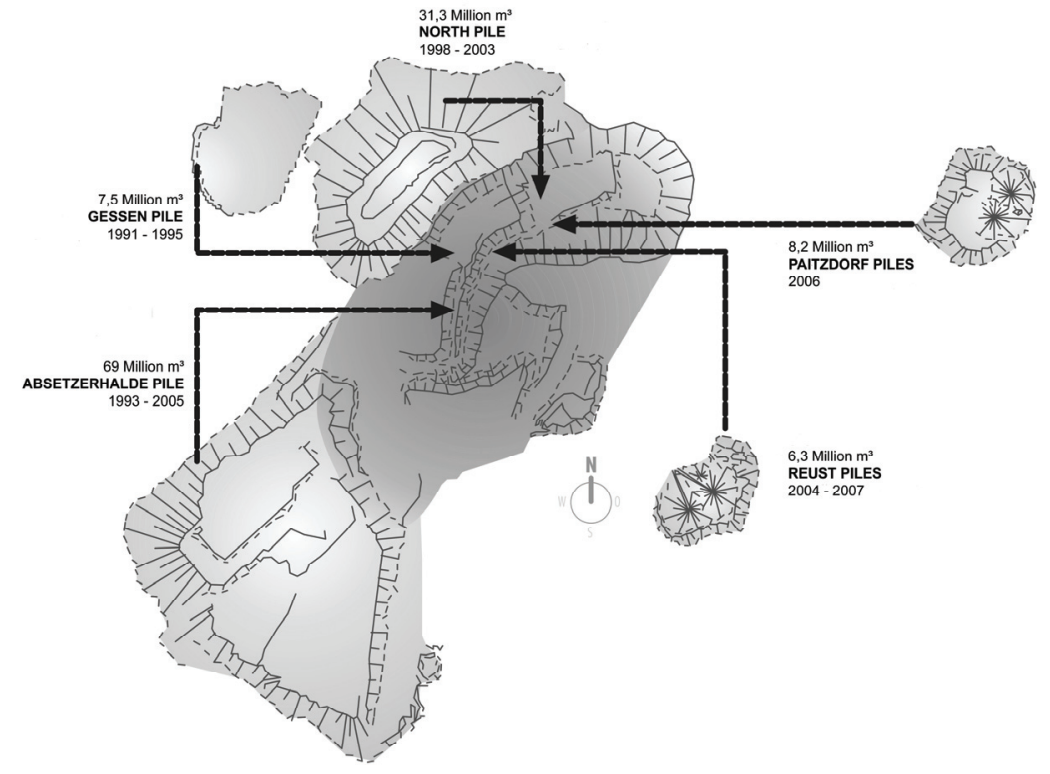

\section{Figure 2 Sequence of waste rock relocation into the Lichtenberg open pit}

The sequence of placing waste rock piles into the worked-out open pit was determined by modelling and forecasting of the long-term environmental impact of the material along the groundwater pathway with regard to the contaminant inventory of the waste rock material. On the base of large-scale field and laboratory investigations to characterize waste rock material according to their acid generating potential, a 
classification into three groups of material was made, and in consequence the open pit volume ( 84 million cubic metres) was divided into three placement zones:

Zone C: $\quad$ Oxygenated zone located near the surface: placement of acid-consuming waste rock materials.

Zone B: $\quad$ Oxygen depleted zone located above the final groundwater level: placement of low-acidgenerating material.

Zone A: $\quad$ Anoxic zone located below the final groundwater level: placement of materials having the highest acid-generating potential.

Figure 3 shows the sequence of pit filling according to the "zone concept".

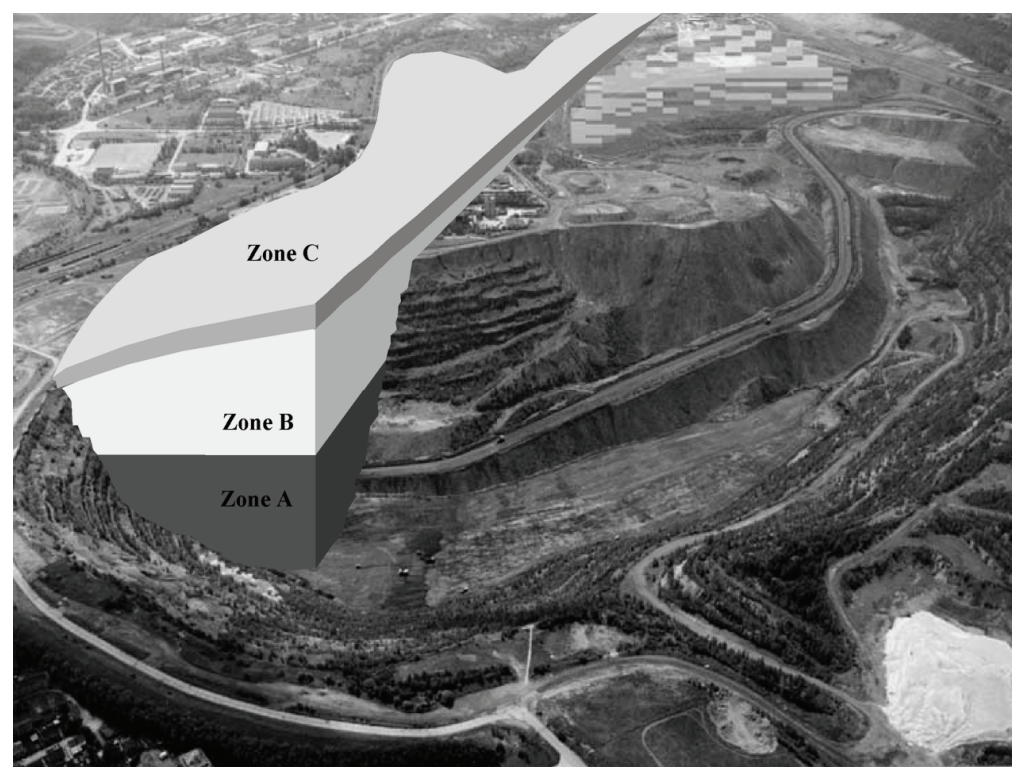

Figure 3 Schematic picture of refilling of the Lichtenberg open pit

For the Beerwalde waste rock pile, due to the distance from the open pit, re-location into the pit or to another site was not a feasible option. To achieve the required long-term geomechanical and hydrological stability, the pile was remediated in-situ. This option included grading and contouring of the slopes followed by their capping with a multiple-layer soil cover. The main target of this option of rehabilitation was to minimize the infiltration of precipitation water into the waste rock and leaching and release of contaminants into the groundwater. Covering of the Beerwalde waste rock pile is shown in Figure 4.

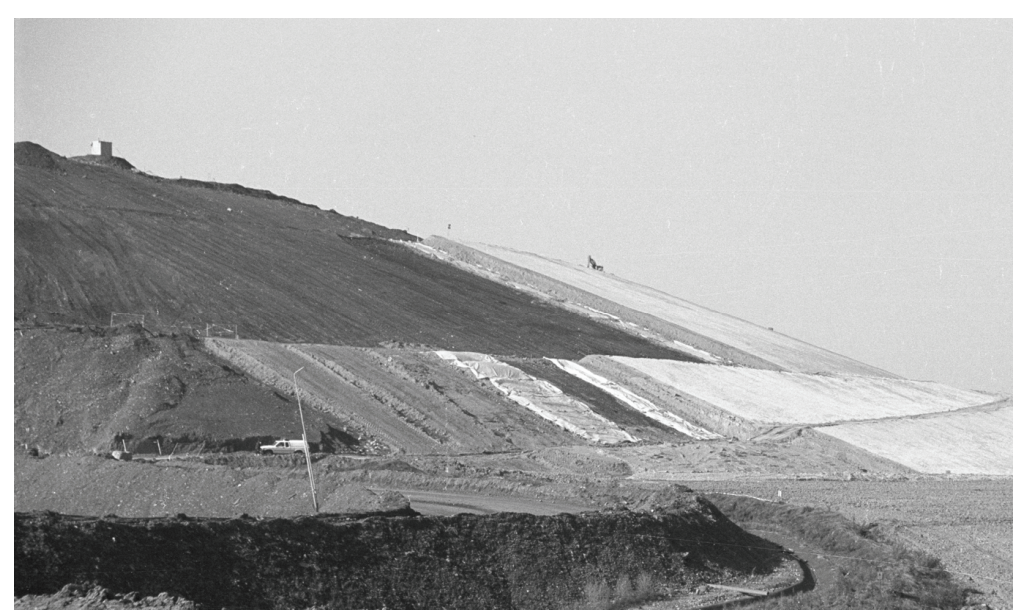

Figure 4 Placement of a multi-layer soil cover on the Beerwalde waste rock pile 


\section{REMEDIATION OF THE TAILINGS PONDS AT THE SEELINGSTÄDT SITE}

WISMUT has responsibility for the rehabilitation of tailings at the Crossen and Seelingstädt sites. Together, the tailings ponds cover an area of more than 570 hectares and contain about 160 million cubic metres of fine-grained residues or tailings from the processing of uranium ore. The tailings were discharged into special impoundments as slurry. This is the reason why the tailings ponds contain great volumes of water in addition to the solid residues, which is both radioactively and chemically contaminated. The tailings impoundments were constructed by erection of dams.

During the first years after the mills shut down, emphasis was placed in immediate remediation efforts to protect workers and the general public against harmful effects. These measures involved the covering of exposed beach areas with soil to avoid wind-blown dispersal of radioactive dust and to minimize radon exhalation. Seepage collection systems were renewed and extended to protect surface waters and aquifers. The contaminated water was collected and returned into the ponds.

In the 1990s, world class environmental restoration technologies, mainly developed in the US and Canada, were studied to arrive at site-specific remedial options for achieving safe storage and long-term stabilisation of the tailings ponds. As a result, dry in-situ stabilisation with partial dewatering of the tailings was identified as the most appropriate option. This option involves the following steps (see also Figure 5):

- Removal, treatment and discharge of supernatant water.

- Interim covering of exposed tailings areas.

- Re-shaping of dam and tailing surfaces.

- Final covering of contoured surfaces.

- Landscaping and re-vegetation.

- Collecting, treatment and discharge of seepage, and long-term monitoring.

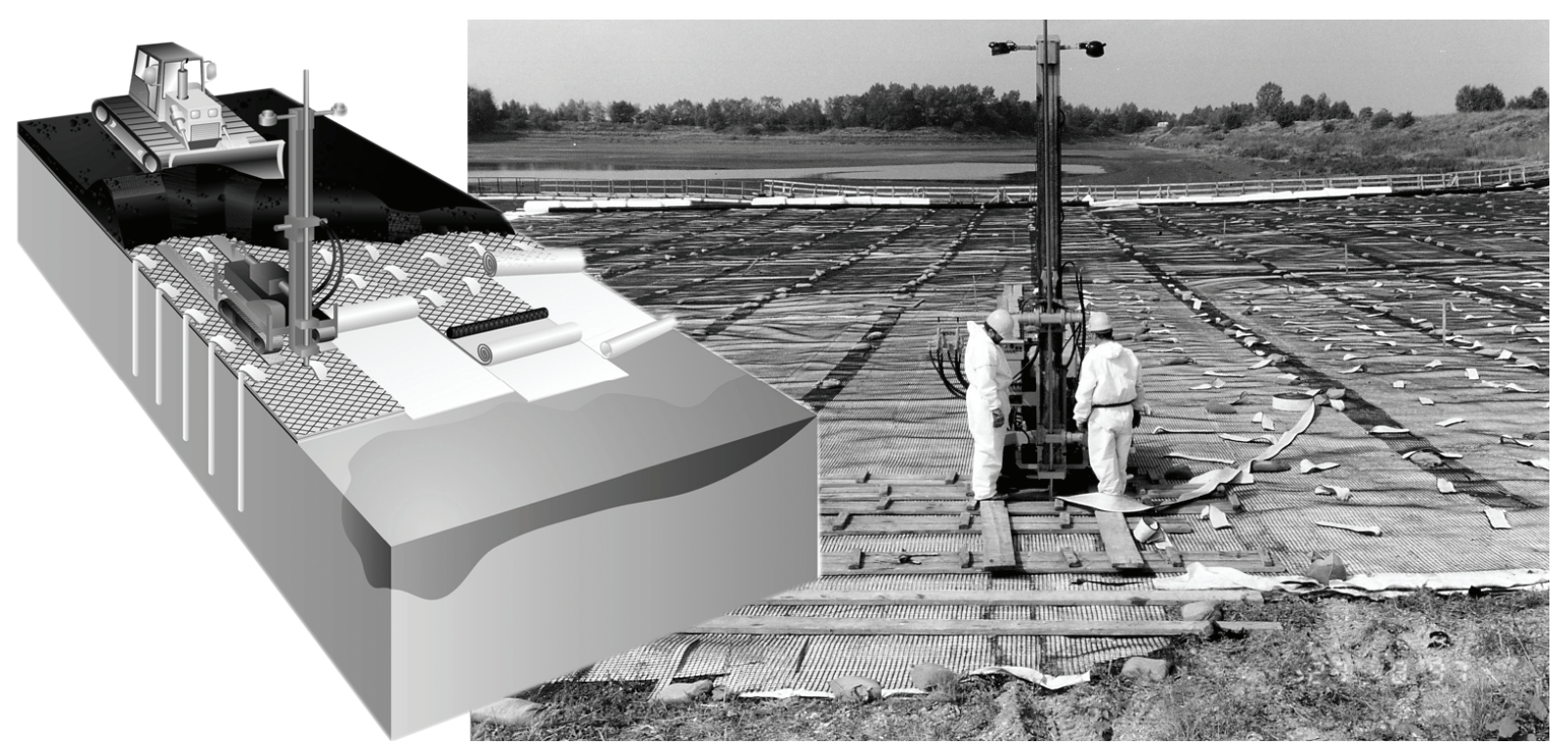

Figure 5 WISMUT technology for dewatering and cover placement at tailings ponds

The cover was designed to minimize both radon exhalation and the infiltration of precipitation. It is a multiple-layer system placed into phases. During the first phase, an interim cover is put in place that consists of man-made materials such as drain mat or geo-grid on which typically waste rock material will be placed. The additional load of the material, which also acts as a drainage layer, accelerates the desired partial tailings dewatering (Lersow, 2001). The effect is enhanced by the installation of vertical trains (wicks) which are 
typically driven down into the tailings to a depth of 5 metres. During the second phase, at the end of essential consolidation (settlement) processes, the final cover will be placed using barren soil and a re-cultivation layer as topsoil.

An essential prerequisite for the safe storage of the tailings ponds is removal of the supernatant water. The contaminants in this water as well as in the pore water released during dewatering must be extracted from the waters and immobilized. This is done in sophisticated water treatment plants in a way to meet discharge limits and to enable the release of the treated water into receiving superficial waters. The residues of the water treatment are disposed in prepared areas of the tailings beaches and finally covered by soil.

A special situation requiring modification of the rehabilitation technology has been met at the Helmsdorf and Culmitzsch tailings pond sites. Due to the difficult geo-technical conditions on the ground in the central areas of the supernatant water lakes, the fine-grained slurries had to be stabilised before water removal (Lersow, 2001). For this purpose, from a floating barge material (sand, gravel, fine-grained waste rocks) was tipped out on the weak slurries ("sub-aquatic tipping"). These works were finished in 2003 at the Helmsdorf site, and in 2005 at the Culmitzsch tailings pond, respectively.

Despite of the difficult geo-technical conditions at the sites, a significant progress has been achieved in rehabilitation of the WISMUT tailings ponds. From most of the ponds, supernatant water has been removed and the so-called interim cover has been established. In some of the areas the final contour of dams is prepared and placement of the final cover is in operation (see Figure 6). To guarantee long-term stability of the final cover, mainly natural material is placed on the interim cover. To make this cost-effective, material from sites close to the ponds is used.

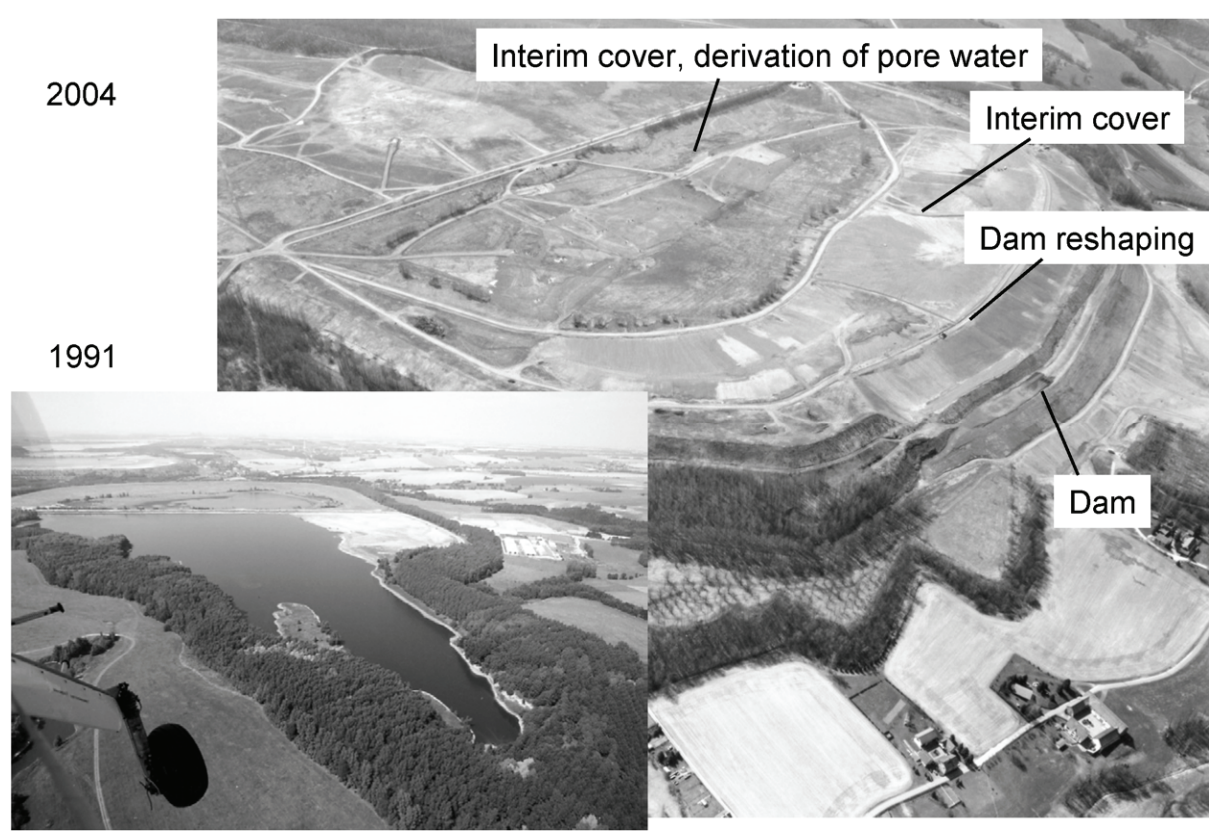

Figure 6 Remediation of the tailings pond Trünzig (1991 vs. 2003)

Concepts for landscaping and after-use of the tailing facilities were agreed with regulatory agencies, communities and other stakeholders. The reclaimed areas are to be integrated into nature conservation schemes. The design will be that of a nature-oriented landscape comprising green spaces and water bodies. Reclamation is aimed at walk away schemes demanding minimum care and maintenance. Finally, the environs of the reclaimed tailings facilities are to be reforested.

\section{WATER TREATMENT ACTIVITIES}

State-of-the-art water treatment plants (WTP) are on stream at all WISMUT sites. These plants use various techniques to remove the radiological main components (uranium, Ra-226) as well as chemic-conventional 
contaminants (As, Mn, Fe, etc.). The feed includes mine water, seepage from mine dumps and tailings ponds as well as water from the consolidation of tailings impoundments. The WTP capacity range is from 100 to $1050 \mathrm{~m}^{3} / \mathrm{h}$. Table 2 provides a picture of water treatment plants operated by WISMUT, their performance parameters, as well as permitted discharge standards. Figure 7 shows the Aue WTP.

Table 2 Survey of water treatment plants operated by WISMUT and of discharge waters

\begin{tabular}{|l|c|l|c|c|c|c|}
\hline Site & $\begin{array}{c}\text { Capacity } \\
{\left[\mathbf{m}^{\mathbf{3}} / \mathbf{h}\right]}\end{array}$ & $\begin{array}{c}\text { Type of feed } \\
\text { water }\end{array}$ & $\begin{array}{c}\text { Main radiological } \\
\text { component }\end{array}$ & \multicolumn{3}{|c|}{ Permitted discharge standard } \\
$\begin{array}{c}\mathrm{U}_{\text {nat }} \\
{[\mathrm{mg} / 1]}\end{array}$ & $\begin{array}{c}\text { Ra-226 } \\
{[\mathrm{Bq} / 1]}\end{array}$ & $\begin{array}{c}\mathrm{U}_{\text {nat }} \text { load } \\
{[\mathrm{t} / \mathrm{a}]}\end{array}$ \\
\hline Aue & 1050 & Mine water & $5 \mathrm{mg} / 1 \mathrm{U}_{\text {nat }}$ & 0.5 & 0.4 & 4.4 \\
\hline Pöhla & 130 & Mine water & $2.5 \mathrm{~Bq} / 1 \mathrm{Ra}-226$ & 0.2 & 0.3 & 0.175 \\
\hline Helmsdorf & 250 & Supernatant water & $10 \mathrm{mg} / 1 \mathrm{U}_{\text {nat }}$ & 0.5 & 0.2 & 0.88 \\
\hline Königstein & 650 & Mine water & $100 \mathrm{mg} / \mathrm{U}_{\text {nat }}$ & 0.3 & 0.4 & 1.7 \\
\hline Seelingstädt & 300 & $\begin{array}{l}\text { Supernatant water, } \\
\text { Seepage water }\end{array}$ & $2 \mathrm{mg} / 1 \mathrm{U}_{\text {nat }}$ & 0.3 & 0.2 & 0.63 \\
\hline
\end{tabular}

* Level order of magnitude

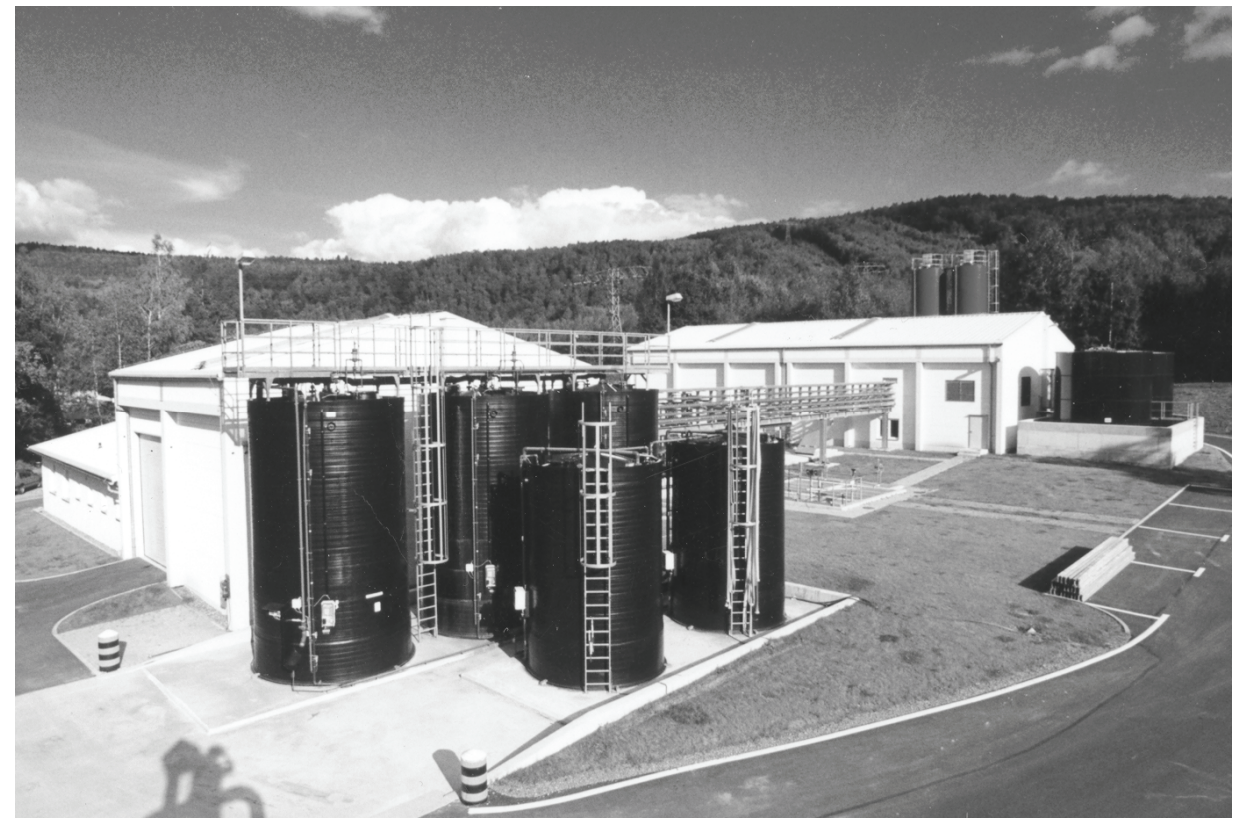

Figure $7 \quad$ View of the Aue water treatment plant

Studies are under way to develop passive water treatment procedures (constructed wetlands, reactive barriers) to replace these high-sophisticated and expensively operated treatment plants in the long-term.

\section{ENVIRONMENTAL MONITORING}

The mission of environmental monitoring is to measure the impact the various liabilities have on the environment as well as to examine the impact remedial action itself has on soil, air and water. Monitoring is not only performed before and after the completion of the remediation works, but also during implementation. Here, a distinction is made between the basic monitoring and the rehabilitation monitoring.

Basic monitoring involves those measurements, which are independent of remedial actions, which use a network of fixed monitoring locations and which are performed according to defined methods and in compliance with legal requirements. In addition, releases and discharges from the sites are also measured. 
The basic monitoring will function as a long-term monitoring network for the surveillance of the postremedial situation and to document remedial performance.

Rehabilitation monitoring involves complex measurements and investigations in advance of the remediation in order to identify the best-suitable options for remediation, and also an environmental surveillance during remediation activities. This kind of monitoring is characterized by its operation for a limited period of time. It also involves the monitoring of the remediation workers radiation exposure.

With advancing remediation progress, the proof of successful performance of the remediation in compliance with the remediation target becomes an important monitoring task. A very illustrative way to demonstrate the successful site clearance is to compare the radon exhalation rate before and after coverage of a waste rock pile. It was found that radon exhalation is dominated mainly by convection and not by radon diffusion. The convection process is driven by temperature differences between the soil air within the pile and the outside air, and the resulting pressure differences. As a consequence, the pattern of radon exhalation rate as well as of the radon concentration free in air (see Figure 8) show both daily and seasonal fluctuations (Schmidt, 2004).

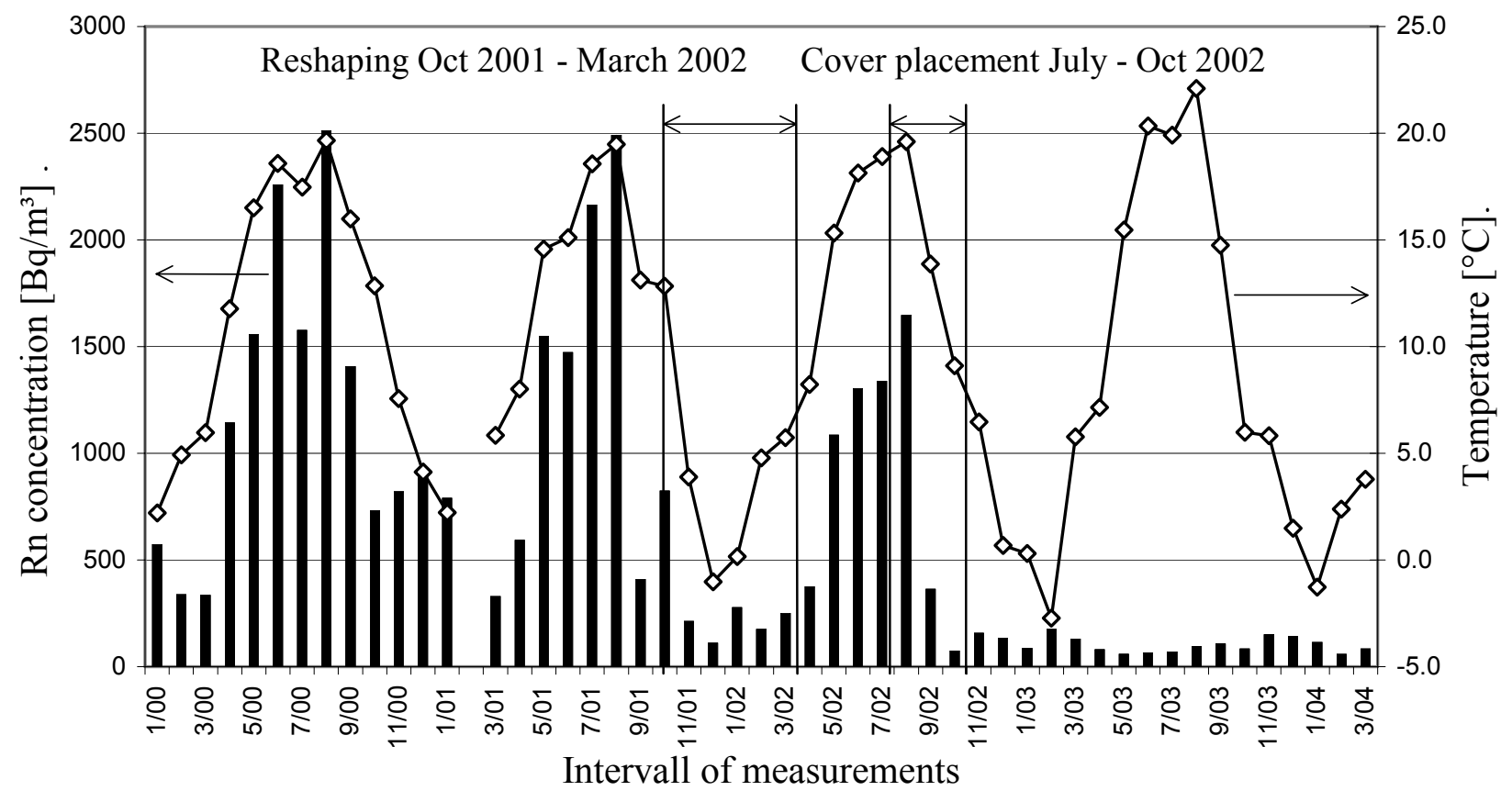

\section{Figure 8 Development of the radon concentration in free air at the toe of a waste rock pile before and after placement of a cover}

The huge amount of data collected makes efficient data management and stringent quality control indispensable. This involves also the testing and certification of instruments and measuring methods including sampling techniques, as well as approval of the source data. Special-purpose computer programmes compile and check the data measured on-site and provided from the laboratories. Qualitycontrolled data are then stored in a central environmental database (Oracle-based). In addition to the specific WISMUT data, the database also contains climate date and data provided by external engineering contractors and consultants.

The environmental database is linked to a geo-graphical information system (GIS-Arcinfo) which allows the interpretation and presentation of environmental data. In recent years, the environmental database was included in an overall data management system called ALWIS. This system includes all technical data, licensing data, photographs, maps, etc. in a Web-based manner. Browsing through ALWIS allows the user to compile in a very efficient and fast way all the information linked to an object or to an individual remedial action. The ALWIS solution is also in application at other environmental organizations, at the authorities and in enterprises. 


\section{STATE OF THE PROJECT AND OUTLOOK}

The work carried out so far in the different fields of decommissioning and remediation has consumed $€ 4.6$ billion. Out of the total of $€ 6.2$ billion this equals to $74 \%$ of the overall budget (state by end-2005).

The underground remedial measures are nearly completely finished, and processing plants have been entirely removed. Current effort is on surface remediation, and almost all of the waste rock piles will be rehabilitated by 2012. The same goes for mine flooding. It is anticipated that stabilisation of tailings impoundments will be completed by 2015. After the rehabilitation work has been finished as planned, some long-term tasks will be left. The long-term activities include:

- Water treatment (technology switch towards less expensive methods, i. e. from conventional to passive treatment, like phyto-remediation, natural attenuation, reactive walls, etc.).

- Management including care and maintenance of restored land ensuring protective reuse.

- Care and maintenance of ancillary mine workings.

- Mine damage control and compensation.

- Long-term environmental monitoring.

- Management of legacy records and information.

At the end of the day, success of the Wismut Remediation Project will be judged by the following criteria:

- Rehabilitated objects no longer represent any serious risk to public health nor any unacceptable environmental impairment.

- Minimum or next to zero care and maintenance.

- Remedial solutions are in line with regional and local land development plans.

The latter point is exemplified by the development of the Schlema-Alberoda community, Aue site. Ranking high among leading Radon spas in Europe before 1945, Schlema was hit hard by uranium mining operations of SDAG Wismut, in particular by the piling up of more than 47 million $\mathrm{m}^{3}$ of waste rock within or very close to residential areas. By 1998, with the mine installations gone and mine dumps rehabilitated, spa activities could be resumed. Present-day Schlema is a booming community which has returned to the top Radon spa locations in Europe.

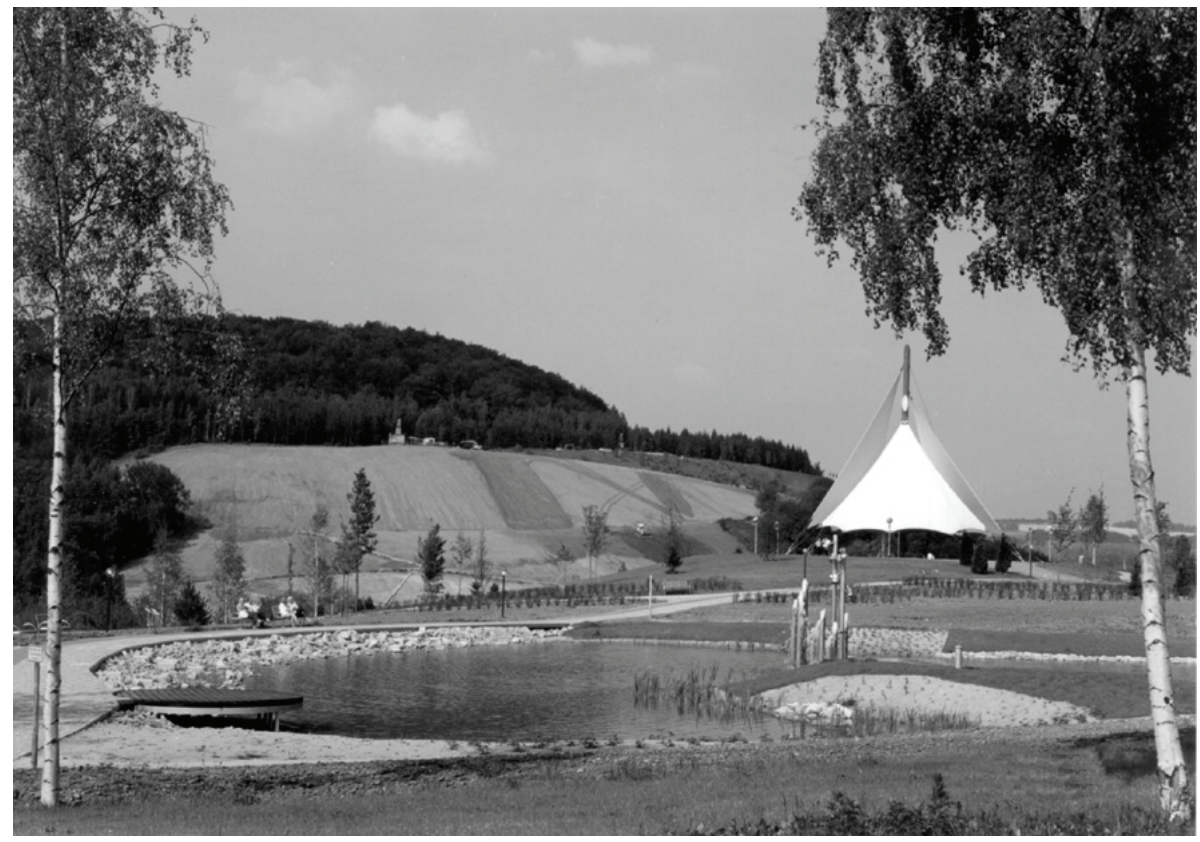

Figure 9 The Schlema spa garden in Schlema-Alberoda 
WISMUT uranium mining in Saxony and Thuringia took place in a densely populated area of a unique cultural landscape of Europe. Accordingly, the rehabilitation of tailings ponds, waste rock piles and mining areas had to include special measures for final landscaping to ensure both the protective reuse and best adaptation to the surroundings. Remediation technologies developed and know-how gained from the WISMUT Project are suitable for use in other parts of the world as well. Experts of the company apply these findings to environmental projects in Germany and abroad. In the framework of the EU TACIS and PHARE programmes, projects in Bulgaria, Estonia, Kazakhstan, the Kyrgyz Republic, in Russia, Slovenia, Romania and Hungary are either under way or completed. Taking into account the local conditions and requirements it was necessary to take specific approaches that led to site-specific solutions. A daughter company, the WISUTEC Wismut Environmental Technology GmbH, was founded in July 2002 to bring the WISMUT know how to the market. The daughter company is becoming more and more the motor for developing future activities of the WISMUT over a hopefully long and successful period.

\section{REFERENCES}

Lersow, M. (2006) Status and results of the Wismut Environmental Remediation Project; presentation at the Second Joint Convention Review Meeting; IAEA, Vienna, May 2006.

Hagen, M., Kunze, C. and Schmidt, P. (2005) Decommissioning and rehabilitation of uranium and thorium production facilities, Kerntechnik, Vol. 70, No. 1-2. Carl Hanser Verlag München, pp. 91-99.

Schmidt, P. (2004) Improvement of the radon situation at former uranium mining and milling sites in East Germany as Part of the Wismut Rehabilitation Project, Internat. Congress Series Vol. 1276, ISBN 0-444-514132-7 (2005), pp. 238-240; presented at the International Conference on High Levels of Natural Radioactivity and Radon Areas, Osaka, Japan, 2004.

Lersow, M. (2001) Deep soil compaction as a method of ground improvement and to stabilization of wastes and slopes with danger of liquefaction, determining the modulus of deformation and shear strength parameters of loose rock. Waste Management 21(2): pp. 161-74 New York, Amsterdam, Tokyo, Singapore, Rio de Janeiro, 2001. 